Max-Planck-Institut für demografische Forschung

Max Planck Institute for Demographic Research

Konrad-Zuse-Strasse 1 - D-18057 Rostock - GERMANY

$\mathrm{Tel}+49$ (0) 3812081 - 0; Fax +49 (0) 3812081 - 202;

http://www.demogr.mpg.de

MPIDR WORKING PAPER WP 2009-017

JUNE 2009

\title{
Alcohol and mortality in Ukraine
}

Nataliia Levchuk (nlevchuk@mail.ru)

This working paper has been approved for release by: Vladimir Shkolnikov (shkolnikov@demogr.mpg.de), Head of the Laboratory of Demographic Data.

(C) Copyright is held by the authors.

Working papers of the Max Planck Institute for Demographic Research receive only limited review. Views or opinions expressed in working papers are attributable to the authors and do not necessarily reflect those of the Institute. 


\title{
Alcohol and mortality in Ukraine
}

\author{
Nataliia Levchuk
}

Institute for Demography and Social Studies at the National Academy of Sciences of Ukraine

26, Panasa Myrnoho str.

01011 Kyiv, Ukraine

Tel: +38044280 8965

Fax: +380442543206

E-mail:nlevchuk@mail.ru 


\title{
Alcohol and mortality in Ukraine
}

\author{
Nataliia Levchuk \\ Institute for Demography and Social Studies at the National Academy of Sciences of Ukraine \\ 26, Panasa Myrnoho str. \\ 01011 Kyiv, Ukraine \\ Tel: +380442808965 \\ Fax: +380442543206 \\ E-mail:nlevchuk@mail.ru
}

\begin{abstract}
Ukraine has experienced a long-term decline in life expectancy since the late 1960s. While spectacular improvement in longevity has been observed in Western countries, the trend in Ukraine has been accompanied by increasing or stagnating mortality. Although many studies indicate that alcohol is one of the leading contributors to low life expectancy in Eastern Europe, little is known about its impact on premature mortality in Ukraine. The aim of this study is to estimate alcoholattributable deaths at working ages (20-64) in Ukraine. We investigate the contribution of alcohol to adult mortality between 1980 and 2007 using a new method for estimating alcohol-attributable fractions by causes of death. We also assess the public health burden of alcohol in terms of length of life losses. We find that in 2007 alcohol-related deaths constituted $40 \%$ and $22 \%$ of all deaths among adult men and women, respectively. The results also indicate that alcohol-related deaths at working ages account for approximately one-third of the male and one-fifth of the female life expectancy difference between Ukraine and western countries. Alcohol is an important public health threat in Ukraine and should be addressed by relevant measures.
\end{abstract}




\section{Table of Contents}

1 Introduction 2

2 Level and patterns of alcohol consumption 3

3 Data and methods 5

4 Results 8

4.1. Correlations between alcohol poisoning and selected causes of death 8

4.2. Estimating alcohol-attributable fractions (AAFs) 9

4.3. Impact of alcohol-attributable deaths on life expectancy 11

$\begin{array}{ll}\text { 5. Discussion and conclusion } & 13\end{array}$

5.1. Data and methods: Strengths and limitations 13

5.2. Substantive results and comparison with other studies 14

$\begin{array}{ll}\text { 5.3. Implications for policy } & 15\end{array}$

$\begin{array}{ll}\text { Acknowledgements } & 16\end{array}$

$\begin{array}{lr}\text { References } & 17\end{array}$

$\begin{array}{ll}\text { Appendix } & 20\end{array}$ 


\section{Introduction}

It has long been known that excessive alcohol consumption increases the risks of various diseases and premature death (Rehm et al. 2004; Anderson 1995; English et al. 1995). The importance of alcohol for unfavourable mortality trends in the former Soviet republics has been widely discussed (Anderson and Hibbs 1992; Shkolnikov et al. 1996; Leon et al. 1997; Bobak et al. 2003; Shkolnikov et al. 2004). The studies suggest that a long-term decrease or stagnation in mortality can be explained by a combination of different factors, such as the spread of unhealthy lifestyle practices (including heavy alcohol drinking), the weakness and ineffectiveness of the health care system, as well as poor standards of living and psycho-social stress (Meslé 2004; Andreev et al. 2003; Cockerham et al. 2006; Field 1995).

The majority of studies on alcohol and health in the former Soviet Union focus on Russia, where the relationship between alcohol and premature mortality has been extensively investigated (Skolnikov and Chervyakov 2000; Nemtsov 2008; McKee et al. 2001; Leon et al. 2007). Much less research has been done on the role of alcohol in Ukraine and other post-Soviet states. The only study on Ukraine known to us is by Godek, who attempted to estimate the impact of alcohol abuse on adult mortality. She found that about $13 \%-16 \%$ of deaths among males, and about $7 \%-10 \%$ of deaths among females were attributable to alcohol (Godek 1998).

Estimating alcohol-related mortality in Ukraine has become increasingly important for several reasons. The first reason concerns the continuing, or even deepening, health and demographic crisis. Over the last two decades, Ukraine (along with many other countries of the former USSR) experienced unprecedented fluctuations in mortality (Shkolnikov et al. 2004; Meslé 2004). Although Ukraine recovered from the crisis of the mid-1990s, the positive changes that followed were short-lived. The current situation remains unfavourable, and does not show any signs of major improvement. According to the latest data, life expectancy at birth is about 12 years lower for Ukrainian men, and about eight years lower for Ukrainian women, than for their Western counterparts. The potential causes of these striking differences in mortality have been discussed in a number of studies (Steshenko et al. 2001; Libanova et al. 2007; Meslé et al. 2008). For example, some studies have suggested that the Chernobyl disaster and environmental problems may have played a role (Steshenko et al. 2001, Zamostyan et al. 2006). Other studies have argued that psychosocial stress produced by rapid and radical socioeconomic and political changes was the major risk factor responsible for the sudden worsening in the health of Ukrainians during the 1990s (Gilmore et al. 2002). Meanwhile, other authors have suggested that the adverse mortality trend may be due to a combination of individual risk factors, such as heavy alcohol consumption, smoking, and poor diet (Cockerham et al. 2006).

The second reason is related to earlier studies on large fluctuations in mortality during the 1980s and 1990s in Ukraine and in other countries of the former USSR. It has been argued that the sudden improvement in mortality during 1985-87 is attributable to the reduction in alcohol consumption due to an anti-alcohol campaign. After these anti-alcohol policies were abandoned, mortality started rising again, reaching a new peak in the mid-1990s (Avdeev et al. 1997; Leon et al. 1997; Skolnikov and Nemtsov 1997; Skolnikov and Chervyakov 2000). The unique context and nature of such large fluctuations in mortality provide us with the opportunity to study the role played by alcohol in overall mortality, albeit indirectly. This is particularly important due to the fact that precise figures about alcohol consumption and its consequences have never been available for Ukraine.

Another important issue concerns the possible underestimation of alcohol-related causes of death in deaths certificates in Ukraine. According to the official data by Statistical Office of 
Ukraine, only 5\% of all deaths that occurred in 2007 were certified as deaths with alcohol in the blood (these were mostly cases of alcohol poisoning). This figure seems to be unreliable in comparison to other post-Soviet countries, for instance to Russia where the level and pattern of drinking resemble those in Ukraine (Leon et al. 2007). A possible reason for this underreporting may be due to the low share of diagnoses based on autopsy results. Additionally, alcohol-related causes of death may be omitted from the death certificate due to requests made by relatives of the deceased. A significant percentage of deaths in which alcohol was likely a contributing factor may have been recorded as having other causes (Tischuk 1997, Nemtsov 2002, Semyonova et al. 2004, Zaridze et al. 2008). Therefore, it is difficult to measure to what extent alcohol consumption has contributed to overall mortality using direct estimations (e.g., mortality due to alcohol poisoning or liver cirrhosis).

Many studies have estimated alcohol-attributable deaths using risk estimates from published literature and from the WHO Comparative Risk Assessment (Corrao et al. 1999; Gutjahr et al. 2001; Rehm et al. 2004; Jones et al. 2008). The major limitation of this approach is that measures of relative risk are not available for Ukraine. There has never been any study attempting to estimate the dose-dependent relationship between alcohol consumption and the risk of death from particular causes in Ukraine. In addition, we could not apply the indirect method by Nemtsov (2008) due to the absence of reliable long-term data on alcohol consumption in Ukraine, and to the nonavailability of forensic reports on accidental and violent deaths.

The present study proposes a new and transparent method based on a linear regression that allows us to quantify the fractions of deaths attributable to alcohol for each major cause of death. Using this method, we were able to make a new series of alcohol-attributable deaths estimates for adult males and females in Ukraine. We expect that this approach can be applied to the study of alcohol-related mortality in other former Soviet republics where alcohol continues to play an important role in mortality at working ages.

\section{Level and patterns of alcohol drinking}

The number of studies on alcohol consumption in Ukraine is quite limited, possibly because of the historically restricted availability of relevant information. Measuring alcohol consumption in the former USSR is not straightforward due to the large quantities of unregistered alcohol consumed. Indirect methods for estimating alcohol consumption have been used in Russia (Treml 1982; Nemtsov 1998, 2008), but these estimates are not available for Ukraine.

It is worth mentioning here that Ukraine led the Soviet republics in sugar production (from sugar beets) prior to the dissolution of the USSR. Large amounts of samogon were being produced from this sugar in the Soviet era. Report Number 14-09/11 (March 7, 1984) entitled "Analiticheskaya zapiska Centralnogo Statisticheskogo Upravlenia Ukrainskoi SSR" (Analytical Report by the Central Statistical Office of the Ukrainian Republic), provided an estimate of sugar purchases in Ukraine based on a survey conducted by the Ukrainian Central Statistical Office in 1983 (the survey included nearly 12,000). Unfortunately, these materials have not been published. The report concluded that almost 200,000 tonnes of sugar were used for the home production of about 20 million decaliters of illicit samogon and 12 million decaliters of grape and fruit wine. From these data, the home production of samogon and wine can be estimated to be 6.4 litres of pure ethanol per capita. It is reasonable to assume that this alcohol was produced mainly for consumption, and that it was not kept for a long time. In 1983, official figures in Ukraine placed per capita annual alcohol consumption at six litres of pure ethanol. Including these figures, the real 
consumption (both state and private production) in Ukraine in 1983 can be estimated to be 12.4 litres of pure ethanol, 6.4 litres of which were homemade.

In the years following Ukrainian independence, sugar production decreased, but still remained one of the leading branches of the agro-industrial complex (Derzhkomstat (2008). It has been suggested that there is a large illegal alcohol market in Ukraine, and that unrecorded alcohol consumption makes up at least two-thirds of all alcohol consumption. A 1995 study by the Ukrainian Alcohol and Drug Information Centre evaluated both the recorded and unrecorded consumption of alcohol between 1980 and 1994 (ADIC-Ukraine (1995). According to this publication, consumption of pure ethanol per capita based on recorded sales ranged between 6.3 litres in 1980 and 2.0 litres in 1994. However, unrecorded consumption of alcohol was about five litres per capita in 1980 and 9.5 litres in 1994. Over time, except during the years of the anti-alcohol campaign, overall alcohol consumption (including unrecorded consumption) was about 11-12 litres of pure ethanol per capita.

Since the beginning of the 1990s, the official accounting of registered alcohol sales has become unreliable. Abolishment of the state monopoly in alcohol production and sales and development of private trading business resulted in a high level of under-registration of alcohol sales. Indeed, the recent official figures have placed per capita annual alcohol consumption in Ukraine at 1.2-1.4 litres of pure ethanol which seems to be unreliable (Derzhkomstat 2008).

For the last several years, the only available estimates of alcohol consumption among adult (15 years and older) in Ukraine were produced by the WHO. According to the WHO Global Status Report on Alcohol (2004), per capita consumption of recorded alcohol in Ukraine was four litres, and unrecorded alcohol consumption was an estimated 7-8 litres of pure ethanol, resulting in overall consumption of 11-12 litres (for both sexes). Figure 1 shows that Ukraine has a high level of overall alcohol consumption, but not the highest in Europe. For comparison, the total alcohol consumption in recent years was around 17.2 litres in Lithuania and the Czech Republic, 15.5 litres in Russia and 14.9 litres in Estonia. According to data from the World Health Survey 2003, total male (ages 15+) per capita consumption in Ukraine was 16.1 litres of pure ethanol, and female per capita consumption was 7.1 litres of pure ethanol (WHO 2004).

Ukraine is a traditional spirits-drinking country, although there is some evidence that beer consumption has recently increased, especially among young people (Pomerleau et al. 2008; The ESPAD Report 2003). Alcohol is often drunk in binges, in which large quantities are consumed in a short space of time, and the proportion of abstainers is relatively low (Webb et al. 2005; Suhrcke et al. 2008; Popova et al. 2007). For example, Pomerleau found that $25 \%$ of men and $4 \%$ of women in Ukraine were defined as heavy episodic drinkers (consumed $\geq 2$ litres of beer or $\geq 750 \mathrm{~g}$ bottle of wine or $\geq 200 \mathrm{~g}$ strong spirits at least once a week) (Pomerleau et al. 2008). This type of drinking culture is labelled as Nordic. In this culture, alcohol is not commonly integrated into a range of everyday activities. Instead, alcohol tends to be associated with celebration, and intoxication is often seen as the main aim of drinking (Fox 2008). 
Figure 1: Recorded and unrecorded adult (15+) per capita alcohol consumption in litres of pure ethanol in Ukraine and selected European countries

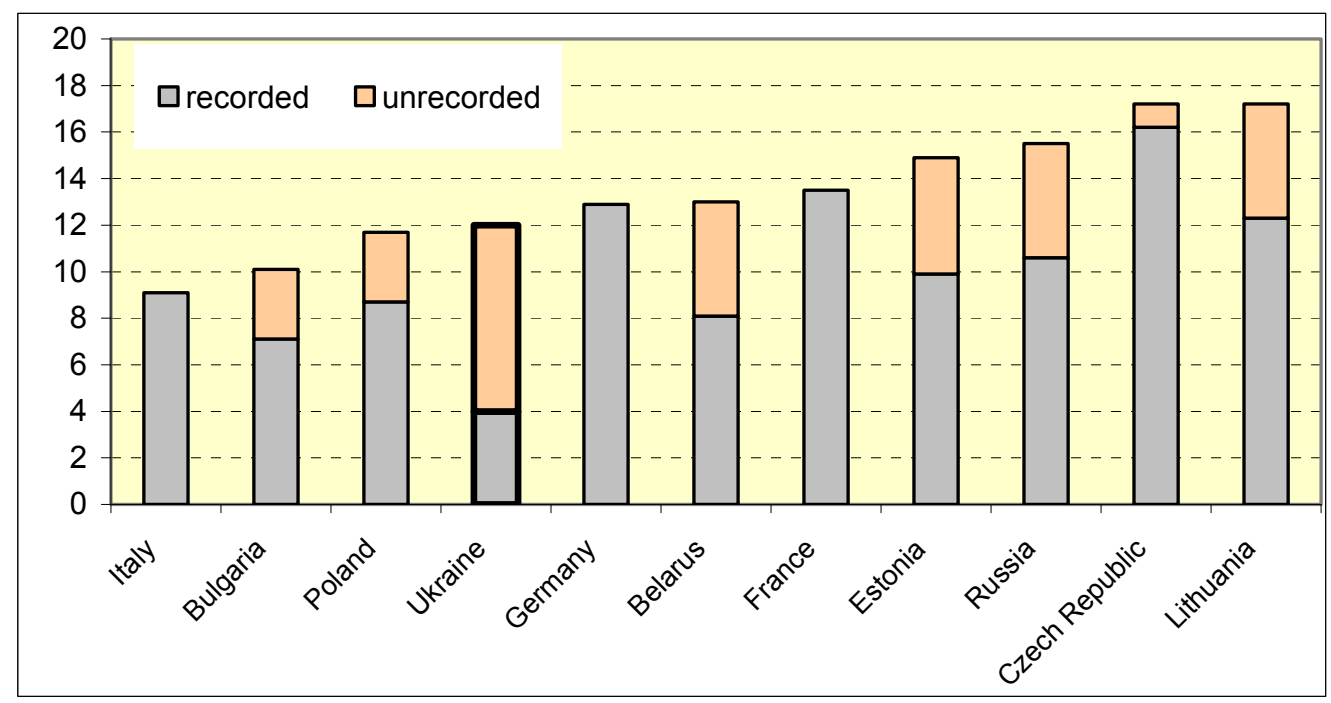

Source: WHO Global Status Report on Alcohol (2004).

In general, alcohol patterns in Ukraine are very similar to those of Russia. Alcohol has common historical roots in these countries, and the existing patterns of drinking are a result of the development of old historical traditions, exacerbated by conditions and alcohol policies during the Soviet period. However, in comparison to Russians, Ukrainians drink somewhat less recorded alcohol, but consume more unrecorded (i.e., homemade) alcohol (WHO 2004). What is unique to Ukraine is that home distillation (samogon) from sugar has deeply rooted traditions, and homebrew production is widespread in rural areas (Goncharuk 2000). The share of the population living in rural areas is greater in Ukraine than in Russia, and these rural areas remain the most important market for unrecorded alcohol. Production of homemade alcohol in Russia consists predominantly of samogon, whereas in Ukraine unrecorded alcohol consumption is of homemade samogon and wine (especially in the western and southern regions) (Goncharuk 2000, Nuzhnyi 2004, Zaigraev 2004, WHO 2004). Therefore, although Ukraine and Russia are very similar in terms of drinking patterns and beverage preferences, the alcohol consumption pattern in Ukraine seems to be somewhat "lighter" than that of Russia, measured by the amount of alcohol consumed and the consequences for the health of the population.

\section{Data and methods}

The present study covers the period from 1980 to 2007. The data sources include the following: cause-of-death data from 1980 to 2000 obtained from INED (Meslé et al., 2008), and data on causes of death for 2001-2007 provided by Statistical Offices of Ukraine. We estimate alcohol-attributable deaths at working ages in Ukraine through the calculation of attributable fractions using an indirect method of estimation. The attributable fraction is generally defined as the proportion of disease risk in a population that would not have occurred if exposure to a risk factor or set of factors had not occurred (Rehm 2004; Gutjahr et al. 2001; Jones et al. 2008). Estimation of alcohol-attributable fractions (AAF) by causes of death was performed using the following steps.

Since alcohol-related mortality is determined by the array of cause-specific death rates, we calculated age-standardised death rates (SDRs) for the range of ages 20 to 64 by causes of death using the European standard population. Since alcohol poisoning is not specified in the Ukrainian ICD-10 implemented in 2005, we reconstructed deaths due to alcohol poisoning in 2005-2007 using 
the approach developed by Meslé and Vallin (Meslé and Vallin 1996; Meslé et al. 2008). In order to ascertain the number of deaths from alcohol poisoning by age, we made a redistribution of deaths from accidental poisoning.

Figure 2: Trends in age-standardised death rates from all causes and from alcohol poisoning for ages 20 to 64: 1980-2007

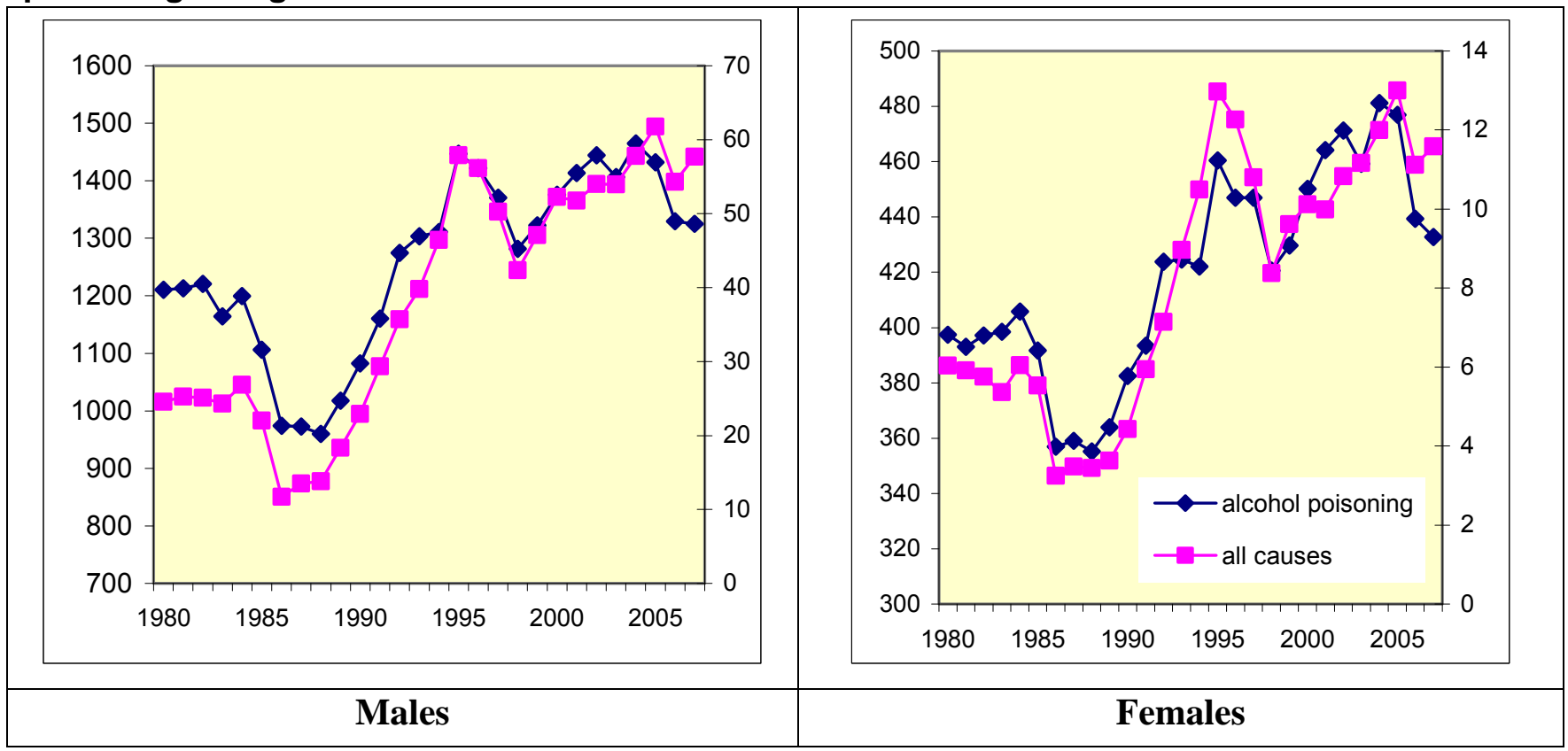

Source: author's calculations based on data from Meslé et al. (2008) and Statistical Office of Ukraine.

We did not have reliable data on per capita alcohol consumption, which was the easiest predictor of alcohol-related harm. It has been suggested that in countries with Nordic pattern of drinking, the death rate from alcohol poisoning is the best predictor variable and marker of changes in heavy alcohol drinking. It seems reasonable to assume that the increase or decrease in alcohol consumption leads to a proportional increase or decrease in the probability of drinking a lethal dose of ethanol. Figure 2 provides strong evidence of a high correlation and a linear relationship between SDRs from all causes of death and SDRs from alcohol poisoning. However, a high positive correlation between alcohol poisoning and other causes does not necessary prove the attribution of deaths to alcohol. Trends in SDR include a linear trend $t$, which could be a main reason for such a correlation. The standard solution in this situation is to eliminate the linear trend. Let $P(t)$ be the observed SDR from alcohol poisoning at ages 20 to 64. If $p(t)$ is a trend-free component of $P(t)$ then covariance $p(t)$ and $t$ is zero and

$$
P(t)=p(t)+\gamma \cdot t
$$

After removing the linear trend, correlations between 25 potentially alcohol-related causes of death and alcohol poisoning were examined using the residuals from the linear fit to the original SDRs. Causes of deaths with significant correlation coefficients were defined as alcohol-related.

It has been suggested that changes in heavy alcohol drinking resulted in changes in alcoholattributable fractions (AAF) of deaths. We propose the following simple model for estimation of AAFs by cause of death $j$. Let $m^{j}$ be standardised death rate at ages 20 to 64 by cause $j$, and assume that $m^{j}$ is a linear function of time $t$ and alcohol poisoning $P$ : 


$$
m^{j}(t, P)=m^{j}(t)+\beta^{j} \cdot P(t)
$$

The first component represents time-dependent mortality from cause $j$, while the second component represents mortality attributable to alcohol consumption. We cannot derive the second component directly from the equation (2) because mortality due to alcohol poisoning can also correlate with time. In this case, there is a risk that the share of alcohol-attributable deaths may by underestimated or overestimated. However, using linear regression method we can represent:

$$
m^{j}(t, P)=\alpha_{0}^{j}+\alpha_{1}^{j} \cdot t+\alpha_{2}^{j} \cdot p(t)+\varepsilon^{j}
$$

where $\varepsilon^{j}$-represents the stochastic error of approximation.

The coefficient $\alpha_{2}^{j}$ in (3) is a measure of proportional changes in cause-specific mortality that depends on the detrended alcohol poisoning (without linear trend), and the coefficient $\beta$ in (2) has the similar meaning but including linear trend. We can assume that $\beta=\alpha_{2}$.

Consequently, the alcohol-attributable fractions by cause of death for the range of ages 20 to 64 can be estimated by the formula:

$$
A A F^{j}(t)=\left(\alpha_{2}^{j} \cdot P(t)\right) / m^{j}(t, P)
$$

where:

$A A F^{j}$ - represents the alcohol-attributable fractions by cause of death for ages 20 to 64 .

Following this procedure, we calculated an alcohol-attributable fraction for each selected cause of death for ages 20 to 64 . In most cases we get valid results. However, the fractions for some years appeared to be higher than one. This occurred for four causes of death for males (influenza and pneumonia, septicaemia, undetermined injury and homicide) and for three causes of death for females (influenza and pneumonia, septicaemia and undetermined injury). Among the possible explanations for this discrepancy are that the variance of mortality from these diseases is almost completely explained by alcohol, or that there has been a decline in the observed death rates over time. In these cases, the procedure was as follows: for each cause of death, the AAF with the maximal value (higher than one) was assumed to be equal to one, and all other AAFs were reduced by the same proportion; while for causes of death that are entirely explained by the impact of alcohol (poisoning by alcohol or mental and behavioural disorders due to use of alcohol), the alcohol-attributable fractions were set to one.

For each selected cause of death, we calculated the alcohol-related SDRs by multiplying the initial SDRs by the corresponding fraction of alcohol-attributable deaths. The sum of cause-specific alcohol-related SDRs represents the total of the alcohol-related mortality. The alcohol-attributable fraction in total deaths was computed by dividing the corresponding total alcohol-related SDR by the all-cause SDR. We assume that the cause-specific AAFs do not change across ages within the age range 20 to 64 . To measure the impact of alcohol-attributable deaths in Ukraine, the life expectancy effects of eliminating the AAFs are calculated using associated single-decrement life tables by causes of death. Additionally, years of life lost due to alcohol-related causes are estimated. All calculations are made separately for men and women. 


\section{Results}

\subsection{Correlations between alcohol poisoning and selected causes of death}

The associations between detrended SDR by alcohol poisoning and SDRs for 25 causes of death are measured. A very tight correlation between alcohol poisoning and ischemic heart disease (IHD) was found. There are also high correlations between alcohol poisoning and the following causes of death: influenza and pneumonia, undetermined injury, suicide and cerebrovascular diseases (for males only). Quite high correlations were also found for accidental drowning, accidental falls and homicide, as well as for cirrhosis of the liver and other and unspecified heart diseases (including alcoholic cardiomyopathy). Neoplasms are excluded from our analyses because of non-significant correlation. The fact that traffic accidents are also not correlated with alcohol poisoning is of interest. It is possible that there is some other set of factors which has changed over time, and which has a larger impact on mortality from this cause. Finally, 18 causes for men and 12 causes for women are identified for quantification of alcohol-attributable deaths (Table 1). ICD-codes for these alcohol-related causes are presented in Appendix1.

Table 1: Pearson correlation coefficients between alcohol poisoning and selected causes of death*

\begin{tabular}{|c|c|c|c|}
\hline \multicolumn{2}{|l|}{ Males } & \multicolumn{2}{|l|}{ Females } \\
\hline Cause of death & $r$ & Cause of death & $r$ \\
\hline Ischemic heart disease ${ }^{1}$ & 0.926 & Ischemic heart disease ${ }^{1}$ & 0.817 \\
\hline Influenza and pneumonia & 0.811 & Other accidents $^{3}$ & 0.707 \\
\hline $\begin{array}{l}\text { Injury, whether accidentally or purposely } \\
\text { inflicted is undetermined }\end{array}$ & 0.802 & Influenza and pneumonia & 0.689 \\
\hline $\begin{array}{l}\text { Mental and behavioural disorders due to } \\
\text { use of alcohol }\end{array}$ & 0.798 & $\begin{array}{l}\text { Mental and behavioural disorders due to use } \\
\text { of alcohol }\end{array}$ & 0.680 \\
\hline Suicide and self-inflicted injury & 0.783 & $\begin{array}{l}\text { Injury, whether accidentally or purposely } \\
\text { inflicted is undetermined }\end{array}$ & 0.676 \\
\hline Other circulatory system diseases & 0.734 & $\begin{array}{l}\text { Other respiratory diseases (excluding } \\
\text { influenza and pneumonia) }\end{array}$ & 0.642 \\
\hline Cerebrovascular diseases & 0.681 & Accidental falls & 0.630 \\
\hline Accidental drowning and submersion & 0.678 & $\begin{array}{l}\text { Other and unspecified heart diseases, } \\
\text { including alcoholic cardiomyopathy }\end{array}$ & 0.604 \\
\hline Accidental falls & 0.646 & Accidental drowning and submersion & 0.599 \\
\hline Homicide & 0.639 & Septicaemia & 0.512 \\
\hline Gastric and duodenal ulcer & 0.637 & Liver cirrhosis & 0.510 \\
\hline Tuberculosis & 0.613 & Diseases of the pancreas & 0.474 \\
\hline Other accidents $^{3}$ & 0.595 & & \\
\hline $\begin{array}{l}\text { Other and unspecified heart diseases, } \\
\text { including alcoholic cardiomyopathy }{ }^{4}\end{array}$ & 0.588 & & \\
\hline Liver cirrhosis & 0.567 & & \\
\hline Septicaemia & 0.577 & & \\
\hline Other diseases of the digestive system ${ }^{5}$ & 0.573 & & \\
\hline Diseases of the pancreas & 0.461 & & \\
\hline
\end{tabular}

Notes: * Residuals from the regression of cause-specific SDRs on time are used

$\mathrm{N}=28 ; \mathrm{p}<0.01$ for each cause

${ }^{1}$ excluding myocardial infarction; ${ }^{2}$ excluding cerebrovascular diseases; ${ }^{3}$ excluding accidental fall, drowning, alcohol poisoning, suicide, homicide and undetermined injury for males; and accidental falls, drowning, alcohol poisoning, suicide and undetermined injury for females; ${ }^{4}$ excluding ischemic heart disease and hypertensive disease; ${ }^{5}$ excluding cirrhosis of liver, diseases of pancreas, and gastric and duodenal ulcer Source: author's calculations based on data from Meslé et al. (2008) and Statistical Office of Ukraine. 


\subsection{Estimating alcohol-attributable fractions (AAFs)}

Results of the linear regression of alcohol-related causes of death as a function of time and alcohol poisoning for males and females are shown in Appendix 2 and Appendix 3. All these conditions have a significant link with alcohol poisoning. Figure 3 shows that estimated fractions of alcoholattributable deaths varied significantly between 1980 and 2007. Trends in overall AAFs for males and females are similar, but male AAFs of deaths are about twice as high as those of females. In the first half of the $1980 \mathrm{~s}$, about $35 \%-40 \%$ of male deaths and about $20 \%$ of female deaths were attributable to alcohol consumption. A marked reduction in AAFs was observed during the antialcohol campaign, declining to $25 \%$ for males and $12 \%$ for females in 1986 . But the downward trend in AAFs had reversed by the mid-1990s, rising to $47 \%$ for males and $25 \%$ for females. Since this increase, some fluctuations have been observed: a decline in 1998, an increase in 2001-2002, and stagnation in recent years. In 2007, alcohol-attributable deaths accounted for $40 \%$ of male and $22 \%$ of female deaths between the ages of 20 to 64 .

Figure 3: Alcohol-attributable fractions for total deaths at ages 20 to 64, 1980-2007

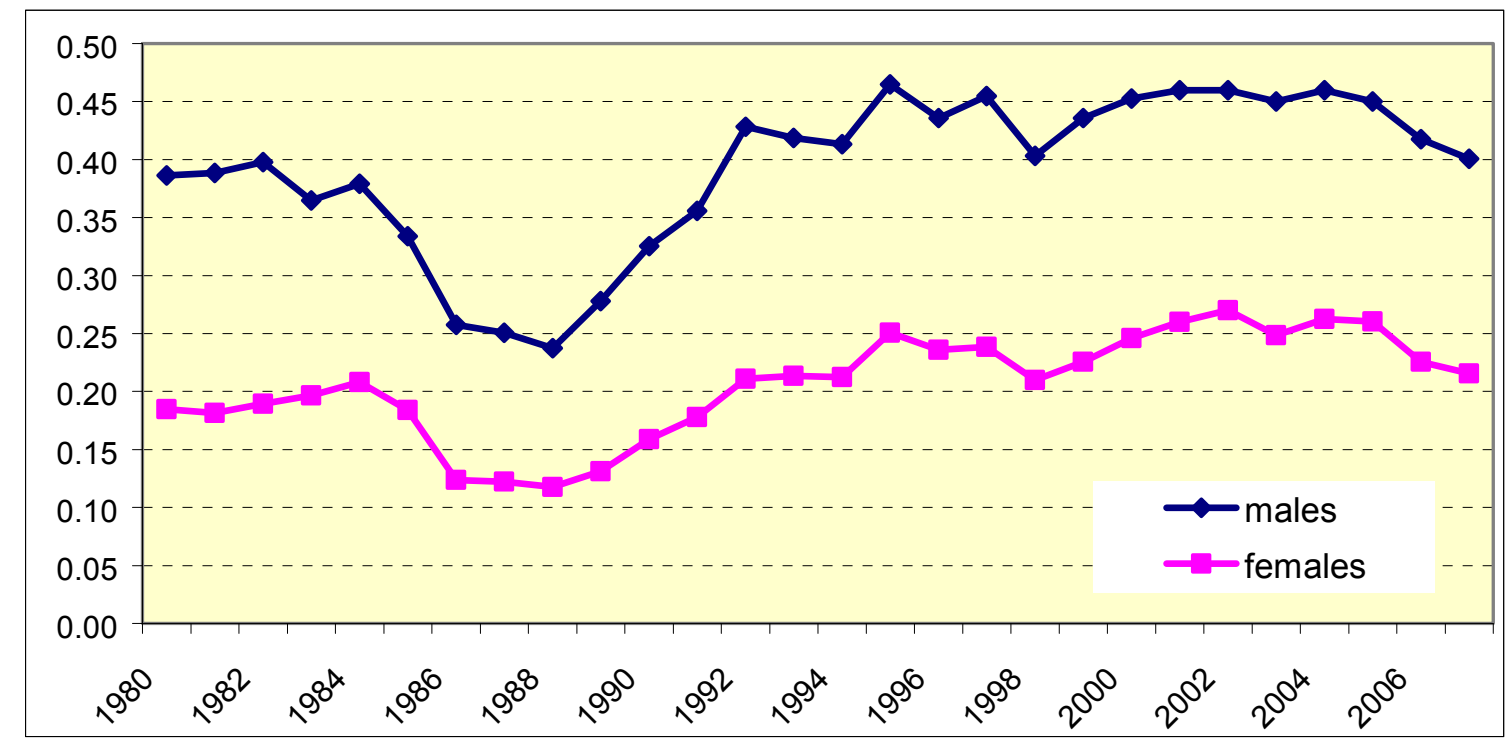

Source: author's calculations based on data from Meslé et al. (2008) and Statistical Office of Ukraine.

The attributable fractions for conditions related to alcohol consumption at five selected points in time (1980, 1986, 1995, 1998 and 2007), which were the years of the highest and the lowest overall mortality in Ukraine, are presented in Table 2 for males and in Table 3 for females. The highest shares of alcohol-attributable deaths among men in 2007 were observed for homicide (0.75), septicaemia (0.73), influenza and pneumonia (0.73), undetermined injury (0.71), accidental drowning (0.67) and suicide (0.66). Alcohol contributed significantly to other and unspecified heart diseases, and played a substantial role in mortality from cirrhosis of the liver and tuberculosis at working ages. Ischemic heart disease is also characterised by a high AAF. There are studies on the role of alcohol as both a risk and protective factor for cardiovascular disease (CVD). Some studies suggest that drinking moderate amounts of alcohol regularly offers some protection against CVD (e.g., Murray and Lopez 1996). In contrast, irregular heavy drinking is associated with an increased risk of cardiovascular events (McKee and Britton 1998). Throughout the observed period, the contribution of alcohol to premature mortality from ischemic heart disease changed, but was still very important. 
Table 2: Alcohol-attributable fractions by causes of death for ages 20 to 64 in 1980, 1986, 1995, 1998 and 2007: males

\begin{tabular}{|l|c|c|c|c|c|}
\hline Cause of death & $\mathbf{1 9 8 0}$ & $\mathbf{1 9 8 6}$ & $\mathbf{1 9 9 5}$ & $\mathbf{1 9 9 8}$ & $\mathbf{2 0 0 7}$ \\
\hline Alcohol poisoning & 1.00 & 1.00 & 1.00 & 1.00 & 1.00 \\
\hline $\begin{array}{l}\text { Mental and behavioural disorders due } \\
\text { to use of alcohol }\end{array}$ & 1.00 & 1.00 & 1.00 & 1.00 & 1.00 \\
\hline Homicide & 0.85 & 0.65 & 0.80 & 0.75 & 0.75 \\
\hline Septicaemia & 0.69 & 0.64 & 0.78 & 0.67 & 0.73 \\
\hline Influenza and pneumonia & 0.71 & 0.65 & 0.58 & 0.56 & 0.73 \\
\hline $\begin{array}{l}\text { Injury, whether accidentally or } \\
\text { purposely inflicted is undetermined }\end{array}$ & 0.81 & 0.74 & 0.90 & 0.72 & 0.71 \\
\hline Accidental drowning and submersion & 0.59 & 0.49 & 0.71 & 0.58 & 0.67 \\
\hline Suicide and self-inflicted injury & 0.58 & 0.46 & 0.72 & 0.56 & 0.66 \\
\hline Gastric and duodenal ulcer & 0.45 & 0.26 & 0.54 & 0.48 & 0.64 \\
\hline Ischemic heart disease & 0.58 & 0.39 & 0.67 & 0.57 & 0.54 \\
\hline Other accidents & 0.33 & 0.24 & 0.49 & 0.35 & 0.40 \\
\hline $\begin{array}{l}\text { Other and unspecified heart diseases, } \\
\text { including alcoholic cardiomyopathy }\end{array}$ & 0.90 & 0.65 & 0.72 & 0.65 & 0.46 \\
\hline Cerebrovascular diseases & 0.41 & 0.25 & 0.41 & 0.38 & 0.46 \\
\hline Tuberculosis & 0.70 & 0.56 & 0.76 & 0.54 & 0.45 \\
\hline Liver cirrhosis & 0.67 & 0.53 & 0.65 & 0.55 & 0.42 \\
\hline Accidental falls & 0.60 & 0.45 & 0.69 & 0.61 & 0.41 \\
\hline Other circulatory system diseases & 0.29 & 0.18 & 0.32 & 0.27 & 0.29 \\
\hline Diseases of the pancreas & 0.49 & 0.37 & 0.56 & 0.46 & 0.26 \\
\hline Other diseases of the digestive system & 0.30 & 0.17 & 0.29 & 0.28 & 0.21 \\
\hline Total & $\mathbf{0 . 3 9}$ & $\mathbf{0 . 2 5}$ & $\mathbf{0 . 4 7}$ & $\mathbf{0 . 4 1}$ & $\mathbf{0 . 4 0}$ \\
\hline
\end{tabular}

Source: author's calculations based on data from Meslé et al. (2008) and Statistical Office of Ukraine.

Table 3: Alcohol-attributable fractions by causes of death for ages 20 to 64 in 1980, 1986, 1995, 1998 and 2007: females

\begin{tabular}{|l|c|c|c|c|c|}
\hline Cause of death & $\mathbf{1 9 8 0}$ & $\mathbf{1 9 8 6}$ & $\mathbf{1 9 9 5}$ & $\mathbf{1 9 9 8}$ & $\mathbf{2 0 0 7}$ \\
\hline Alcohol poisoning & 1.00 & 1.00 & 1.00 & 1.00 & 1.00 \\
\hline $\begin{array}{l}\text { Mental and behavioural disorders due } \\
\text { to use of alcohol }\end{array}$ & 1.00 & 1.00 & 1.00 & 1.00 & 1.00 \\
\hline Septicaemia & 0.71 & 0.58 & 0.76 & 0.58 & 0.73 \\
\hline $\begin{array}{l}\text { Injury, whether accidentally or } \\
\text { purposely inflicted is undetermined }\end{array}$ & 0.75 & 0.66 & 0.74 & 0.61 & 0.62 \\
\hline Influenza and pneumonia & 0.60 & 0.54 & 0.48 & 0.54 & 0.60 \\
\hline $\begin{array}{l}\text { Other respiratory diseases } \\
\text { (excluding Influenza and pneumonia) }\end{array}$ & 0.16 & 0.16 & 0.42 & 0.32 & 0.47 \\
\hline Ischemic heart disease & 0.50 & 0.39 & 0.60 & 0.52 & 0.46 \\
\hline Accidental drowning and submersion & 0.43 & 0.34 & 0.53 & 0.36 & 0.44 \\
\hline Other accidents & 0.35 & 0.27 & 0.46 & 0.43 & 0.44 \\
\hline Accidental falls & 0.44 & 0.30 & 0.48 & 0.42 & 0.38 \\
\hline $\begin{array}{l}\text { Other and unspecified heart } \\
\text { diseases, including alcoholic }\end{array}$ & 0.60 & 0.52 & 0.66 & 0.61 & 0.37 \\
cardiomyopathy & & & & & 0.24 \\
\hline Liver cirrhosis & 0.47 & 0.37 & 0.48 & 0.44 & 0.16 \\
\hline Diseases of the pancreas & 0.20 & 0.13 & 0.24 & 0.22 & $\mathbf{0 . 2 2}$ \\
\hline Total & $\mathbf{0 . 1 8}$ & $\mathbf{0 . 1 2}$ & $\mathbf{0 . 2 5}$ & $\mathbf{0 . 2 1}$ & \\
\hline
\end{tabular}

Source: author's calculations based on data from Meslé et al. (2008) and Statistical Office of Ukraine.

While women are less affected by alcohol-attributable deaths than men, they are also at risk of damaging their health through alcohol consumption. The AAFs for women are much lower. In 2007, septicaemia, undetermined injury, influenza and pneumonia had the highest female AAFs. 
Additionally, alcohol accounted for a considerable percentage of premature deaths from other respiratory diseases, accidental falls and drowning.

Between 1980 and 2007, male-female differences in AAFs increased slightly. The main differences were for external causes, cirrhosis of the liver and diseases of the pancreas. Males experienced excess mortality from alcohol-attributable accidental drowning. In 2007, the AAF for this cause in males was estimated to be 1.5 times higher than the rate for females. Of the deaths from ischemic heart disease among males, 54\% in 2007 were attributed to alcohol, while the corresponding contribution of alcohol-attributable death among females was $46 \%$.

Both for males and females, the proportional changes of alcohol-attributable deaths by individual diagnoses between 1980 and 1986, and between 1986 and 1995, revealed a clear relationship: increases in AAFs by causes of death in the first half of the 1990s are the reversals of decreases in the same causes during the anti-alcohol campaign. Thus, our results confirm similar results obtained earlier for Russia: the observed fluctuations in mortality and dramatic drops in life expectancy in the first half of 1990s can be largely explained by the impact of the rise in alcohol consumption that followed the prior decrease during the anti-alcohol campaign (Avdeev et al. 1997; Leon et al. 1997; Skolnikov and Chervyakov 2000; Skolnikov and Nemtsov 1997).

\subsection{Impact of alcohol-attributable deaths on life expectancy}

Table 4 shows that alcohol-related mortality at ages 20 to 64 has a strong impact on life expectancy. In 1980, expected gains in life expectancy at birth were estimated to be 3.5 years for males and 0.9 years for females. By 1995, gains in life expectancy had increased to 5.2 years in males and to 1.4 years in females. In 2007, the life expectancy effects of eliminating the AAFs were 4.5 and 1.3 years for males and females, respectively.

Table 4: Effects of elimination of AAFs of deaths on life expectancy, and years of life lost (YLL) due to alcohol-attributable deaths at ages 20 to 64

\begin{tabular}{|l|c|c|c|c|c|c|}
\hline \multirow{2}{*}{} & \multicolumn{2}{|c|}{$\begin{array}{c}\text { Potential gain in life } \\
\text { expectancy at birth (years) }\end{array}$} & \multicolumn{2}{c|}{$\begin{array}{c}\text { YLL } \\
\text { (thousand person-years) }\end{array}$} & \multicolumn{2}{c|}{$\begin{array}{c}\text { Contribution } \\
\text { to total YLL, \% }\end{array}$} \\
\cline { 2 - 7 } & Males & Females & Males & Females & Males & Females \\
\hline 1980 & 3.47 & 0.85 & 1497.6 & 347.8 & 23.30 & 6.87 \\
\hline 1986 & 1.94 & 0.57 & 866.2 & 226.7 & 15.01 & 4.57 \\
\hline 1995 & 5.19 & 1.37 & 2861.2 & 625.4 & 32.17 & 10.18 \\
\hline 1998 & 4.15 & 1.05 & 2118.8 & 454.3 & 27.53 & 8.34 \\
\hline 2007 & 4.52 & 1.25 & 2308.7 & 510.6 & 27.49 & 9.23 \\
\hline
\end{tabular}

Source: author's calculations based on data from Meslé et al. (2008) and Statistical Office of Ukraine.

Figures 4 and 5 show, for males and females, the impact of each individual alcohol-related cause of death on life expectancy at birth in 1995 and 2007. The major contributions to the gain in male life expectancy are produced by reductions in ischemic heart disease, alcohol poisoning, cirrhosis of the liver, undetermined injuries and other accidents. For example, 1.10 and 0.96 years were gained due to lower rates of ischemic heart disease in 1995 and 2007, respectively. In 2007, the contributions of undetermined injuries, suicide and cerebrovascular diseases were much lower than in 1995, while the gains produced by cirrhosis of the liver, other und unspecified heart diseases, influenza and pneumonia increased over the period. 
Figure 4: Effects of elimination of AAFs by causes of death at ages 20 to 64 in 1995 and 2007: Gains in male life expectancy at birth in years

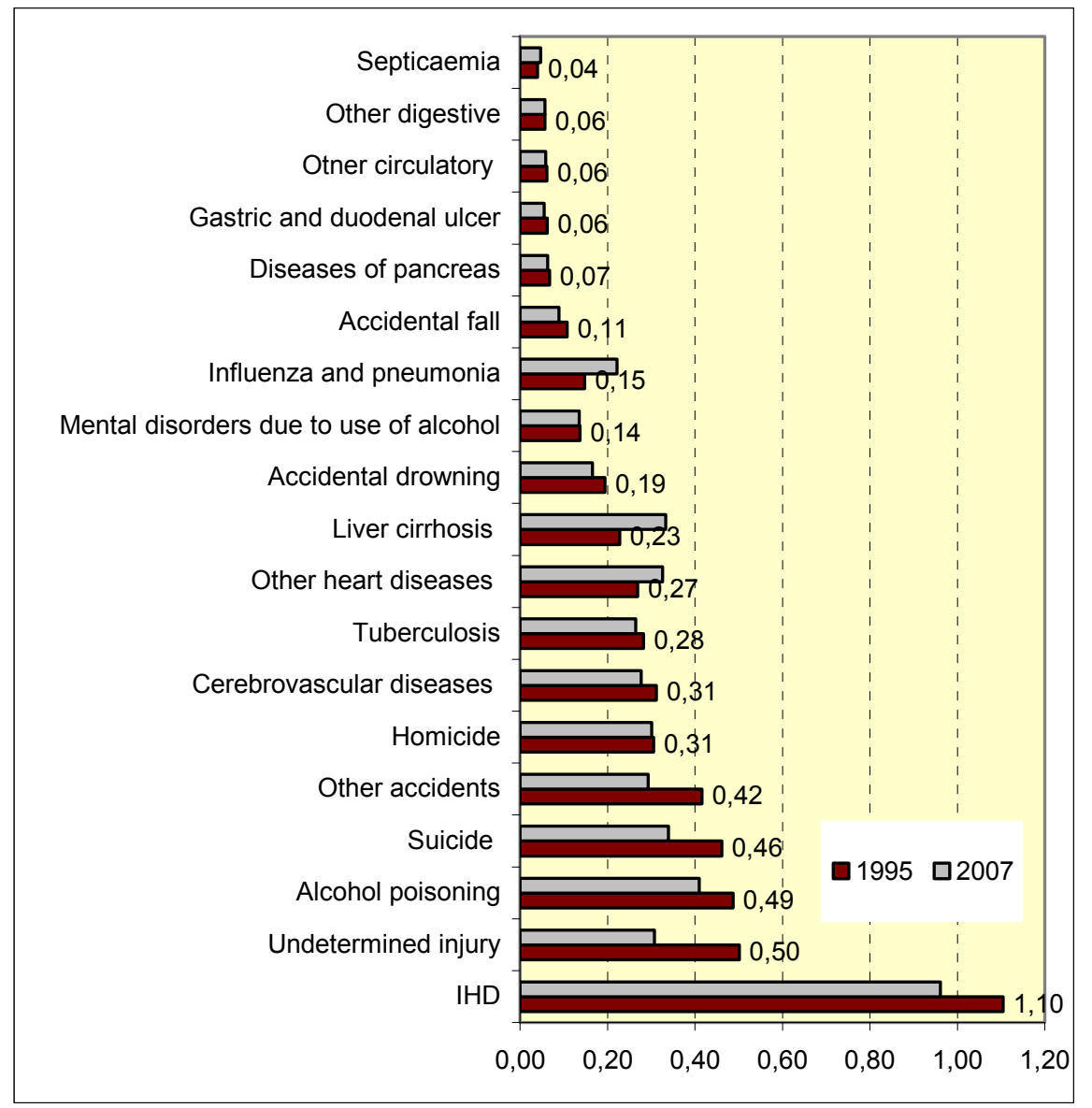

Source: author's calculations based on data from Meslé et al. (2008) and Statistical Office of Ukraine.

Similarly, ischemic heart disease is the most important cause of death in terms of gain in life expectancy for females. When alcohol-attributable deaths from ischemic heart disease are not considered, the gains in female life expectancy are shown to be 0.61 years in 1995 and 0.51 years in 2007. Alcohol poisoning, cirrhosis of the liver, undetermined injury and other accidents also produce substantial effects on the life expectancy of women. For alcohol poisonings, cirrhosis of the liver, and influenza and pneumonia, the elimination effects in 2007 were found to be 1.2 times greater than those in 1995. In contrast, the effects of alcohol-attributable deaths from ischemic heart disease and other respiratory conditions have been reduced. In males, for the majority of conditions examined, the expected gains in life expectancy are greater than those for females, particularly for all kinds of violence, ischemic heart disease, alcohol poisoning and cirrhosis of the liver.

Additionally, we calculated the years of life lost (YLL) due to alcohol-attributable deaths at ages 20 to 64 . Years of life lost shows how much additional time could be lived if the mortality differences between Ukraine and the average Western country were eliminated. Our results indicated that YLL (for both sexes) was an estimated 2819.3 thousand person-years in 2007, or about 33 years of life lost per one alcohol-attributable death at ages 20 to 64. Male YLL constituted up to two-thirds of all YLL due to alcohol-attributable deaths (Table 4). In 2007, years of life lost due to alcohol-related mortality at ages 20 to 64 accounted for $27.5 \%$ of total male and $9 \%$ of total female YLL. 
Figure 5: Effects of elimination of AAFs by causes of death at ages 20 to 64 in 1995 and 2007: Gains in female life expectancy at birth in years

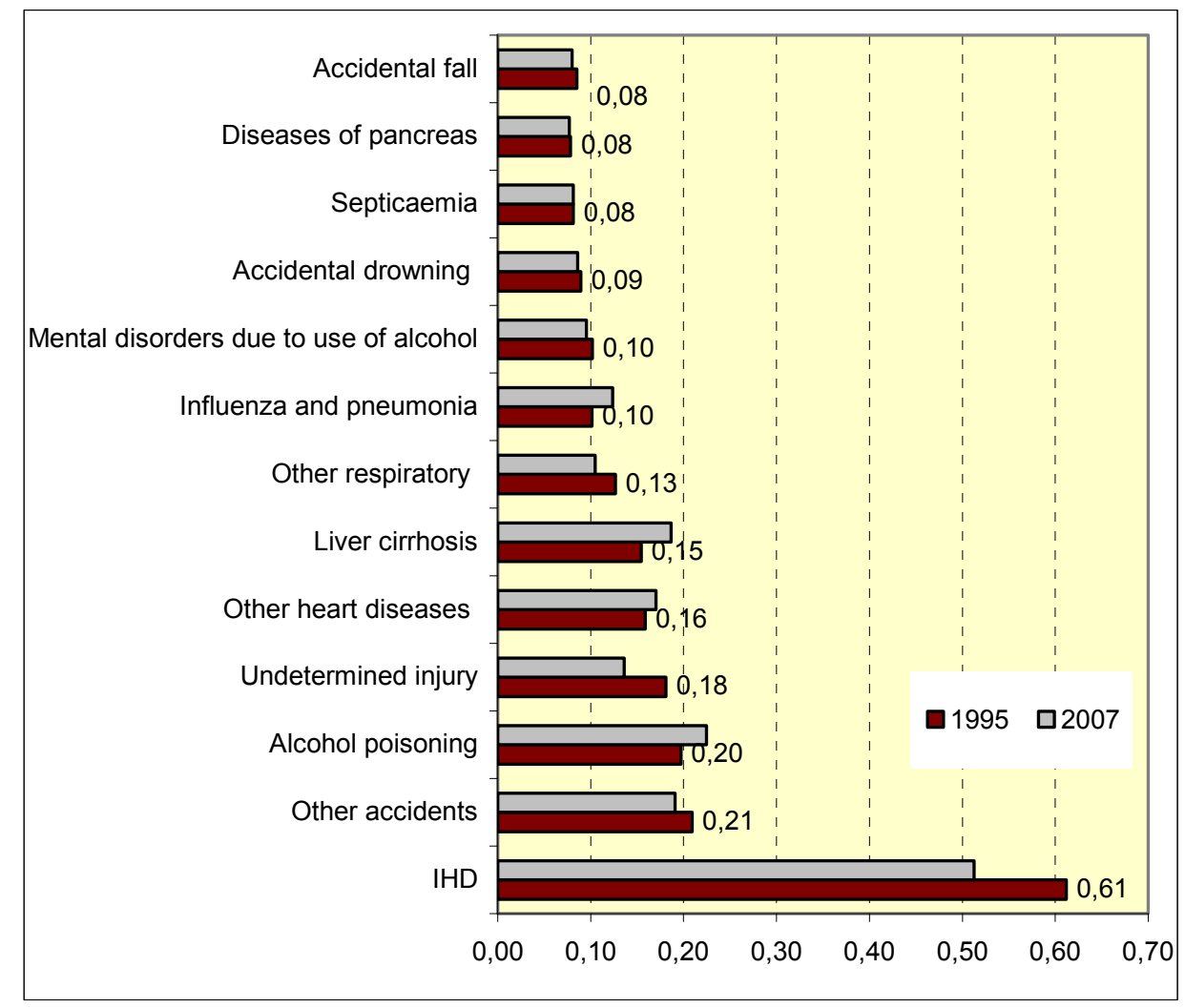

Source: author's calculations based on data from Meslé et al. (2008) and Statistical Office of Ukraine.

\section{Discussion and conclusion}

\subsection{Data and methods: strengths and limitations}

To our knowledge, this is the first published estimation of alcohol-attributable fractions of deaths in Ukraine. We estimated alcohol-attributable deaths using an indirect method. There are several limitations to consider when interpreting the results of this study.

The first problem concerns the quality of cause-of-deaths data used for the estimation. According to the official data obtained from the Statistical Office of Ukraine, only one-third of all deaths that occurred in 2007 included forensic diagnoses resulting from autopsies. It should be noted that, because most of the diagnoses in death certificates are written before autopsy findings are obtained, it is possible that the latter are not taken in account.

Second, we applied a new method which enables indirect estimation of the proportions of deaths attributable to alcohol. The basic assumption of this method is that there is a linear relationship between the selected causes of deaths and alcohol poisoning. We considered the causespecific death rate as a function of mortality from alcohol poisoning and time. It is important to keep in mind, however, that this relationship can be more complicated because of a possible correlation between mortality from alcohol poisonings and time. Also, the using slopes derived from the formula (2) for the estimation of AAFs seem to be a relatively crude solution, but this approach enabled us to avoid a possible underestimation of alcohol-attributable deaths, which would have occurred if we had used formula (2) directly.

It is worth mentioning here that the estimated cause-specific alcohol-attributable fractions of deaths should not be seen as precise, due to the aforementioned problems with cause-of-death 
diagnostics. For example, taking into account the finding by Zaridze et al. (2008) that many alcohol-related deaths are wrongly attributed to diseases of circulatory system, it could be suggested that the AAFs for IHD in our study are overestimated. However, these limitations would not bias our findings regarding the overall AAFs (for total deaths at working ages). The key advantages of our approach are that we estimated alcohol-attributable deaths in Ukraine using easily available cause-of-death data, and by applying a simple indirect method based on linear regression. Furthermore, it might be possible to apply our approach for estimating AAFs to other countries with high levels of alcohol-related problems and similar patterns of drinking (like Russia, Belorussia and the Baltic countries). Thus, this study offers a new instrument for comparative analysis of postSoviet countries in terms of alcohol-related mortality.

\subsection{Substantive results and comparison with other studies}

Our findings provide clear evidence that alcohol plays a substantial role in excessive adult mortality in Ukraine. The links between alcohol consumption and various chronic diseases, as well as violence, provide strong arguments in support of this thesis. A total of 18 causes for men and 12 for women were found to be correlated with alcohol poisoning. Males experienced far greater alcoholrelated mortality than females. In 2007, an estimated $40 \%$ of deaths among men and $22 \%$ of deaths among women at ages 20 to 64 were attributable to the harmful effects of alcohol. Alcohol abuse reduced life expectancy at birth by 4.5 years for males and by 1.3 years for females. People whose deaths are due to excessive alcohol consumption lose an average of about 33 years of life. Ischemic heart diseases, undetermined injuries and other accidents, alcohol poisoning, as well as cirrhosis of the liver, produce the greatest gains in life expectancy due to the elimination of respective AAFs of deaths.

Our estimations are generally close to estimates that were obtained in more direct ways in other post-Soviet countries. For example, a case control study in Izhevsk (Russia), based on individual-level data, found that heavy drinking was responsible for $43 \%$ of all deaths among males aged 25-54 in 2002-2005 (Leon et al. 2007). Nemtsov (2008) estimated from the forensic reports on blood alcohol levels that about one-third of all male deaths (all ages included) in Russia are related to alcohol. At the same time, our estimates are higher than those produced by Godek (1998), who estimated that about $13 \%-16 \%$ of deaths among males, and about $7 \%-10 \%$ of deaths among females (of working ages) in Ukraine are attributable to alcohol. This could by explained by differences in the methods applied. Godek computed the number of deaths attributable to alcohol using a set of AAFs originally provided by the Centers for Disease Control and Prevention in the USA (CDC, 1990). There are some reasons to be cautious about using relative risk estimates obtained using nonUkrainian data, including the fact that the existing AAFs do not take into account the high degree of damage caused by binge drinking.

Our results support other findings on the crucial role of alcohol as a factor in mortality fluctuations that were observed in the countries of the former USSR over the course of the 1990s (Avdeev et al. 1997; Leon et al. 1997, 2007; Skolnikov and Chervyakov 2000; Skolnikov and Nemtsov 1997; McKee et al. 2001). There is a significant correlation between the increase in the AAFs of deaths in 1986-1995, and the prior decrease in 1980-1986 in Ukraine. These trends may reflect the negative effects of both the abandonment of the anti-alcohol campaign and the socioeconomic shock of the abrupt switch to a market economy after the collapse of the USSR. The high proportion of alcohol-attributable deaths in Ukraine is probably explained by a combination of the amount of alcohol consumed (including illicitly produced alcohol) and the pattern of drinking. 


\subsection{Implications for policy}

Measuring alcohol-attributable deaths helps to estimate impact of alcohol on health and mortality, and can be a useful indicator for developing national alcohol strategies intended to reduce alcohol's harmful consequences. The link between alcohol and excessive adult mortality in Ukraine can now substantially supported by evidence. Our study found that a large proportion of deaths in the Ukraine may be attributed to alcohol, and that these deaths therefore contribute significantly to the low levels of life expectancy in Ukraine, especially among men. Alcohol-attributable deaths at working ages are estimated to account for approximately one-third of the male and one-fifth of the female life expectancy gaps between Ukraine and Western countries. Given the high level of alcohol-related mortality in Ukraine, there is, therefore, a need for a range of interventions to prevent or reduce the harm caused by alcohol. Recent studies have shown that a number of efficient and cost-effective strategies for reducing alcohol consumption are available (Österberg 2004; Room 2005; Framework for alcohol policy in the WHO European Region 2006). The most efficient approach is to implement multiple policies that employ the following strategies: increase alcohol prices, reduce the availability of alcohol, introduce measures that discourage drunk driving, provide alcohol education, and seek to identify and treat alcohol-related personal problems in the early stages (Österberg 2004). However, alcohol policy should be sensitive to cultural diversity and national specificity. In the case of Ukraine, the actions taken should strongly emphasise the fight against illegal alcohol production, as well as the consumption of homemade alcohol beverages and surrogates that sharpen the negative consequences of alcohol consumption.

This study also shows that the elimination of AAFs would have increased life expectancy considerably, but that this improvement would not have radically reduced the gap in life expectancies between Ukraine and Western countries. Moreover, the overall proportions of alcoholattributable death for males and females in 2007 were very similar to those in 1980, but life expectancies were much lower. Hence, alcohol should not be viewed as the only decisive factor behind the adverse mortality pattern in Ukraine. It has been suggested that other factors, such as improvement in access to and quality of health care, could make substantial contributions to efforts to increase life expectancy (Nolte et al. 2004; Andreev et al. 2003; Lekhan et al. 2004).

Finally, alcohol policy could be considered in a broader political context. The common drinking culture in Ukraine is socially constructed and accepted because it is seen as natural. The problem is that the institutional environment and the poor living conditions do not tend to encourage healthy lifestyles (Cockerham 2000), and might be contributing to the reproduction and maintenance of negative alcoholic traditions, including binge drinking. In Ukraine, primary prevention and positive lifestyle practices which would encourage individuals to take responsibility for their own health have been neither encouraged nor implemented. In addition, anti-alcohol campaigns in the mid-1980s had a negative impact on public attitudes to alcohol policies, namely, any state regulation of alcohol. Therefore, an effective and comprehensive policy aimed at decreasing alcohol consumption and reducing alcohol-related harm is needed, but its success is dependent on the state's willingness to pursue certain kinds of policies, and on societal acceptance. The key consequence is that changes in individual behaviour are strongly associated with institutional changes. This policy could be implemented through the promotion of healthy activities and the creation of institutional conditions which support an individual's choice to lead a healthy lifestyle. 


\section{Acknowledgements}

I am particularly indebted to my mentor Evgueny Andreev for providing valuable ideas, helpful suggestions and insightful discussion about the most important issues of my research. It is also my pleasure to express my sincere gratitude to Vladimir Shkolnikov, Domantas Jasilionis and Dmitry Jdanov for teaching me advanced demographic methods of mortality research, and for offering helpful advice at various stages of my work. I am particularly grateful to Aiva Jasilioniene, Olga Grigorieva and Pavel Grogoriev for professional and personal support during my stay at the Max Planck Institute. Special thanks go to Evgenia Bystrov, Nathaniel Boyden and all IMPRSD Winter Fellows 2008-09 for their advice and the congenial atmosphere they provided.

This paper was produced during the stay of author at the International Max Planck Research School for Demography in 2008-2009 in Rostock, Germany.

\section{References}

ADIC-Ukraine (1995). Alcohol ta narkotyky v Ukraini [Alcohol and Drugs in Ukraine]. Alcohol and Drug Information Center (ADIC). Kyiv, 96 p. [In Ukrainian].

Anderson, P. (1995). Alcohol consumption and all-cause mortality. Addiction 90, 481-484.

Anderson, S., Hibbs, V. (1992). Alcoholism in the Soviet Union. International Social Work 35, 441-453.

Andreev, E.M., Pridemore, W.A, Shkolnikov, V., Antonova, O. (2008). An investigation of the growing number of deaths of unidentified people in Russia. European Journal of Public Health 18, 252-257.

Avdeev, A., Blum, A., Zakharov, S., Andreev. E. (1997). Reaction d'une population heterogene a une perturbation. Un modele d'interpretation des evolutions de mortalite en Russie. Population (French Edition) 1, 7-44.

Bobak, M., Murphy, M., Rose, R., Marmot, M. (2003). Determinants of adult mortality in Russia. A study based on sibling's survival. Epidemiology 14, 603-611.

Britton, A., McKee, M. (2000). The relationship between alcohol and cardiovascular diseases in Eastern Europe: explaining the paradox. Journal of Epidemiology and Community Health 54, 328-332.

Centers for Diseases Control and Prevention (CDC) (1990). Alcohol-related mortality and years of potential life lost - Unites States, 1987. Morbidity and Mortality Weekly Report 39,173-178.

Chenet, L., McKee, M., Leon. D., Shkolnikov, V., Vassin, S. (1998). Alcohol and cardiovascular mortality in Moscow: new evidence of a casual association. Journal of Epidemiology Community Health 52, 772-774.

Cockerham, W.C. (2000). Health lifestyle in Russia. Social Science and Medicine 51, 1313-1324.

Cockerham, W.C., Hinotea, B.P., Abbottb, P. (2006). Psychological distress, gender, and health lifestyles in Belarus, Kazakhstan, Russia, and Ukraine. Social Science and Medicine 63, 2381-2394.

Corrao, G., Bagnardi, V., Zambon, A., Arico, S. (1999). Exploring the dose-response relationship between alcohol consumption and the risk of several alcohol-related conditions: a metaanalysis/ Addiction 94, 1551-1573. 
Derzhkomstat (2008). Statystychnyi shorichnyk (Ukrainian Statistical Yearbook). Kyiv, Statistical Offices of Ukraine - 571 p. [in Ukrainian].

Field, M. (1995). The health crisis in the former Soviet Union: A report from the post-war zone. Social Science and Medicine 41, 1469-1478.

Fox, A. (2008). Sociocultural factors that foster or inhibit alcohol-related violence. In: Alcohol and violence: exploring patterns and responses. International Center for Alcohol Policies, 1-28.

Framework for alcohol policy in the WHO European Region (2006). WHO Regional Office for Europe. $-26 \mathrm{p}$.

Gilmore, A.B.C., McKee, M., Rose, R. (2002). Determinants of and inequalities in self-perceived health in Ukraine. Social Science and Medicine 55, 2177-2188

Gmel, G., Rehm, J., Frick U. (2001). Methodological approaches to conducting pooled crosssectional time series analysis: the example of the association between all-cause mortality and per capita alcohol consumption for men in 15 European states. European Addiction Research 7, 128-37.

Godek, L.M. (1998). Increasing adult mortality in Ukraine, 1965-1994: The contributions of alcohol and tobacco abuse. [PhD thesis]. Michigan: The University of Michigan.

Goncharuk V. (2000). Pytna sprava. Yak use pochynalosya (Alcohol history of Ukraine). Alcohol and Tobacco 2-3, 5-10 [in Ukrainian].

Gutjahr, E., Gmel. G., Rehm. J. (2001). Relation between average alcohol consumption and disease: an overview. European Addiction Research 7, 117-127

http://www.euro.who.int/document/E82969.pdf

Jones, L., Bellis, M.A., Dedman, D., Sumnall, H., Tocque, K. (2008). Alcohol-attributable fractions for England. Alcohol-attributable mortality and hospital admissions. Centre for Public Health, Faculty of Health and Applied Social Sciences, Liverpool John Moores University, North West Public Health Observatory. -, 53 p.

Lekhan, V., Rudiy, V., Nolte, E. (2004). Health care systems in transition: Ukraine. Copenhagen, WHO Regional Office for Europe on behalf of the European Observatory on Health Systems and Policies, 2004.

Leon, D. A., Chenet, L., Shkolnikov, V.M., et al. (1997). Huge variation in Russian mortality rates 1984-94: artefact, alcohol, or what? Lancet 350, 383-388.

Leon, D.A, Saburova, L., Tomkins, S., Andreev, E., Kiryanov, N., McKee, M., Shkolnokov, V.M. (2007). Hazardous alcohol drinking and premature mortality in Russia: a population based case-control study. Lancet 369, 2001-2009.

Libanova, E., Levchuk, N., Ryngach, N., Rudnyckij, O., Poniakina, S., Shevchuk, P. (2007). Smertnist naselennya prazesdatnoho viku v Ukraini [Mortality at Working Age in Ukraine]. Kyiv: Institute for Demography and Social Studies at the NAS of Ukraine. -- 211 p. [in Ukrainian].

McKee, M., Britton, A. (1998). The positive relationship between alcohol and heart disease in Eastern Europe: potential physiological mechanisms. Journal of the Royal Society of Medicine 91, 402-407.

McKee, M., Leon, D.A. (2005). Social transition and substance abuse. Addiction 100, 1205-1209

Meslé F., Vallin. J., Pyrozhkov S., Shkolnikov V., Adamets S. (2008). Smertnist ta prychyny smerti $\mathrm{v}$ Ukraini u XX stolitti (Mortality and causes of death in Ukraine for the $20^{\text {th }}$ century). Paris: INED, MSE. - 415 p. [in Ukrainian].

Meslé, F. and Vallin, J. (1996). Reconstructing long-term series of causes of death. Historical methods 29, 72-87. 
Meslé, F., (2004). Mortality in Central and Eastern Europe: long-term trends and recent upturns. Demographic Research (Special Collection 2. Determinants of Diverging Trends in Mortality), 46-70.

Murray, C.J.L., Lopez, A. (1996). The Global Burden of Disease. London: Oxford University Press.

Nemtsov, A. V. (2002) Alcohol-related harm losses in Russia in the 1980s and 1990s. Addiction, 97, 1413-1425.

Nemtsov, A.V. (1998). Alcohol-related harm and alcohol consumption in Moscow before, during and after a major anti-alcohol campaign. Addiction 93 (10), 1501-1510.

Nemtsov, A.V. (2008). Alcogolnaya istoriya Rossii: noveishiy period [Russia's latest alcoholic history] Moskow: Librocom [in Russian].

Nolte, E., Scholz, M., McKee, M. (2004). Progress in health care, progress in health? Patterns of amenable mortality in central and eastern Europe before and after political transition. Demographic Research. Special Collection 2, Article 6, Determinants of Diverging Trends in Mortality, 139-162.

Nuzhnyi, V. (2004) Chemical composition, toxic, and organoleptic properties of noncommercial alcohol samples. In: Haworth, A. and Simpson, R. (eds.) MoonshineMarkets: Issues in Unrecorded Alcohol Beverage Production and Consumption..Brunner-Routledge, New York, pp. 177-199.

Österberg E (2004). What are the most effective and cost-effective interventions in alcohol control? Copenhagen, WHO Regional Office for Europe (Health Evidence Network report). -14 p.

Pomerleau, J., McKee, M., Rose, R., Christian W. Haerpfer, C.W., Rotman, D., Tumanov, S. (2005). Drinking in the Commonwealth of Independent States - evidence from eight countries. Addiction 100, 1647-1668.

Pomerleau, J., McKee, M., Rose, R., Haerpfer, C.W., Rotman, D., Tumanov, S. (2008). Hazardous alcohol drinking in the former Soviet Union: a cross-sectional studies of eight countries. Alcohol and Alcoholism 43, 351-359.

Popova S., Rehm J., Patra J., Zatonski W. (2007) Comparing alcohol consumption in Central and Eastern Europe to other European countries. Alcohol and Alcoholism 42, 465-473.

Rehm, J., Room, R., Monteiro, M., Gmel, G., Graham, K., Rehn, N., Sempos, C.T., Frick, U., Jernigan, D. (2004). Alcohol use. In: Ezzati, M., Lopez, A.D., Rodgers, A., Murray C.J.L. (ed.). Comparative quantification of health risks. Global and Regional Burden of disease Attributable to Selected Major Risk Factor. Geneva: WHO, 959-1108.

Rehm, J., Sulkowska, U., Mańczuk, M., Boffetta, P., Powles, J., Popova, S., Zatoński, W. (2007). Alcohol accounts for a high proportion of premature mortality in Central and Eastern Europe. International Journal of Epidemiology 36, 458-467.

Room, R., Babor, T., Rehm, J. (2005). Alcohol and public health: a review. Lancet 365, 519-530.

Semyonova V.G., Gavrilova N.S., Evdokushkina G.N., Gavrilov L.A. (2004). Kachestvo medicostatisticheskih dannyh kak problema sovremennogo zdravookhranenia (Data quality of medical statistics as a problem of modern Russian health care). Public Health and Disease Prevention 2, 11-18. [in Russian].

Shkolnikov, V., Meslé F., Vallin. J. (1996) Health crisis in Russia. I. Recent trends in life expectancy and causes of deaths from 1970 to 1993. Population, an English Selection, 8, 123-154.

Shkolnikov, V.M., Andreev, E.M., Leon. D.A., McKee, M., Mesle, F., Vallin, J. (2004). Mortality Reversal in Russia: the story so far. Hygiea internationalis 4, 29-80.

Shkolnikov, V.M., Chervyakov, V.V. (2000). Politika po controlyu krisisnoi smertnosti v Rossii v perekhodnyi period [Policies for the control of the transition's mortality crisis in Russia]. Moscow, UNDP [in Russian]. 
Shkolnikov, V.M., Nemtsov, A.V. (1997). The anti-alcohol campaign and variations in Russian mortality. In: Premature Deaths in the New Independent States, 239-261.

Steshenko, V. (2001). Demographichna krysa v Ukraini [Demographic crisis in Ukraine]. Steshenko V. (ed.). Kyiv: Institute of Economics, 2001. - 450 p. [in Ukrainian].

Stickley, A., Leinsalu, M., Andreev, E., Razvodovsky, Y., Vagero, D., McKee, M. (2007). Alcohol poisoning in Russia and the countries in the European part of the former Soviet Union, 1970-2002. European Journal of Public Health, Vol. 17, No. 5, 444-449.

Suhrcke, M., Walters, S.,Mazzuco, S., Pomerleau, J., McKee, M., Haerpfer, C.W. (2008). Socioeconomic differences in health, health behaviour and access to health care in Armenia, Belarus, Georgia, Kazakhstan, Kyrgyzstan, the Republic of Moldova, the Russian Federation and Ukraine. WHO, $55 \mathrm{p}$.

Szucs, S., Sarvary, A., McKee, M., Adany, R. (2005). Could the high level of cirrhosis in Central and Eastern Europe be due partly to the quality of alcohol consumed? An exploratory investigation. Addiction 100, 536-542.

The ESPAD Report 2003 (2004). Alcohol and Other Drug Use Among Students in 35 European Countries. The Swedish Council for Information on Alcohol and Other Drugs (CAN), Stockholm.

Tischuk E.A. (1997). Medico-statisticheskie aspekty deistviia alkogolia kak prichiny smertnosti naselenia (Medico-statistical aspects of the effect of alcohol consumption on mortality). Public Health Service of the Russian Federation 2, 34-36. [In Russian].

Treml, V.G. (1982) Alcohol in the USSR. A statistical study. Duke Press Policy Studies, Durham, NC.

Vallin, J., Meslé, F. (2004). Convergences and divergences in mortality. A new approach of health transition. Demographic research. Special collection 2, Article 2, 11-44.

Webb C.P.M., Bromet, E.J., Gluzman, S., Tintle, N.L., Schwarz, J.E., Kostyuchenko, S., Havenaar, J.M. (2005). Epidemiology of heavy alcohol use in Ukraine: findings from the World Mental Health Survey. Alcohol and Alcoholism 40, 327-335.

WHO (2004). Global Status Report on Alcohol 2004. Geneva: WHO. .

Zaigraev G. (2004) The Russian model of noncommercial alcohol consumption. In: Haworth, A. and Simpson, R. (eds.). Moonshine Markets. Issues in unrecorded alcohol beverage production and consumption. Brunner-Routledge, New York, pp. 31-40.

Zamostyan, P., Saenko, J., Pryvalov, J., Khodorivska, N., Rogozin, O. (2006). Security and development of Chernobyl communities: situation analysis. Kyiv: Institute of Sociology, 2006. $-251 \mathrm{p}$.

Zaridze, D., Maximovitch, D., Lazarev, A., Igitov, V., Boroda, A., Boreham, J., Boyle, P., Peto, R., Boffetta, P. (2008). Alcohol poisoning id a main determinant of recent mortality trends in Russia: evidence from a detailed analysis of mortality statistics and autopsies. International Journal of Epidemiology 38, 143-153. 


\section{Appendix}

\section{Appendix 1: ICD-codes of selected alcohol-related causes of death. Correspondence between ICD 9 (Soviet classification) and ICD 10}

\begin{tabular}{|c|c|c|c|}
\hline & Cause of death & ICD 9 (175) & ICD 10 \\
\hline 1 & Tuberculosis & $9-13,43$ & A15-A19, B90 \\
\hline 2 & Septicaemia & 25 & A40-A41 \\
\hline 3 & $\begin{array}{l}\text { Ischemic heart disease (excluding myocardial } \\
\text { infarction) }\end{array}$ & $92-95$ & $120,124-\mid 25$ \\
\hline 4 & $\begin{array}{l}\text { Other and unspecified heart disease (including } \\
\text { alcoholic cardiomyopathy) }\end{array}$ & $96-97$ & $\begin{array}{c}30-140, \quad 142.0-5,7-9, \quad 144-151, \mid 26- \\
128,142.6\end{array}$ \\
\hline 5 & Cerebrovascular diseases & $98-99$ & $160-169$ \\
\hline 6 & Other circulatory system diseases & $100-102$ & $170-178,180-189,195-199$ \\
\hline 7 & Influenza and pneumonia & 104-107 & J10-J18 \\
\hline 8 & $\begin{array}{l}\text { Other respiratory diseases (excluding influenza and } \\
\text { pneumonia) }\end{array}$ & $103 ; 108-114$ & J00-J09; J19-J98 \\
\hline 9 & Liver cirrhosis & $122-123$ & $\mathrm{~K} 70, \mathrm{~K} 74$ \\
\hline 10 & Diseases of the pancreas & 126 & K85-K86 \\
\hline 11 & Gastric and duodenal ulcer & $115-116$ & K25-K26 \\
\hline 12 & Other diseases of the digestive system & $\begin{array}{c}117-121 ; 124- \\
125 ; 127\end{array}$ & $\begin{array}{l}\text { K04-K24; K20-K22; K27-K66; K71- } \\
\text { K73; K75-K76; K80-K84; K90-K92 }\end{array}$ \\
\hline 13 & Accidental falls & 166 & W00-W19 \\
\hline 14 & Accidental drowning and submersion & 168 & W65-W74 \\
\hline 15 & Suicide and self-inflicted injury & 173 & $\mathrm{X} 60-\mathrm{X} 84$ \\
\hline 16 & Homicide & 174 & X85-X99 \\
\hline 17 & Alcohol poisoning & 163 & - \\
\hline 18 & $\begin{array}{l}\text { Injury, whether accidentally or purposely inflicted is } \\
\text { undetermined }\end{array}$ & 175 & Y10-Y34 \\
\hline 19 & Other accidents & $\begin{array}{l}160-162, \quad 164- \\
165, \quad 167, \quad 169- \\
172,174-175\end{array}$ & $\begin{array}{l}\text { V01-V97; X00-X39; X50-X59; Y00- } \\
\text { Y09; Y35-Y36; Y40-Y89; W20-W64, } \\
\text { W75-W99 }\end{array}$ \\
\hline 20 & $\begin{array}{l}\text { Mental and behavioural disorders due to use of } \\
\text { alcohol }\end{array}$ & 73,75 & F10 \\
\hline
\end{tabular}


Appendix 2: Results for linear regression of alcohol-related causes of death as a function of time and alcohol poisoning ${ }^{1}$, males (formula 3)

\begin{tabular}{|c|c|c|c|c|c|c|c|}
\hline Cause of death & $\alpha_{1}^{j}$ & SE & $\alpha_{2}^{j}$ & SE & $\alpha_{0}^{j}$ & SE & $\mathrm{R}^{2}$ \\
\hline Ischemic heart disease & $5.972^{\star \star \star}$ & 0.246 & $2.896^{* \star *}$ & 0.237 & $\begin{array}{l}150.508^{*} \\
* *\end{array}$ & 0.185 & 0.967 \\
\hline Influenza and pneumonia & $1.015^{\star \star \star}$ & 0.074 & $0.496^{\star \star \star}$ & 0.072 & $4.818^{\star \star}$ & 1.234 & 0.904 \\
\hline Diseases of the pancreas & $0.287^{* * *}$ & 0.031 & $0.078^{* \star *}$ & 0.030 & $3.785^{\star * *}$ & 0.515 & 0.787 \\
\hline Accidental falls & $0.237^{* \star *}$ & 0.036 & $0.145^{\star \star \star}$ & 0.034 & $8.232^{* \star *}$ & 0.590 & 0.714 \\
\hline $\begin{array}{l}\text { Other diseases of the digestive } \\
\text { system }\end{array}$ & $0.230^{\star \star \star}$ & 0.021 & $0.070^{\star \star *}$ & 0.020 & $8.322^{* \star *}$ & $0.344^{* * *}$ & 0.833 \\
\hline Liver cirrhosis & $2.291^{* * *}$ & 0.271 & $0.515^{\star *}$ & 0.261 & $10.222^{* *}$ & $0.494^{* *}$ & 0.751 \\
\hline $\begin{array}{l}\text { Accidental drowning and } \\
\text { submersion }\end{array}$ & $0.101^{*}$ & 0.066 & $0.293^{* * *}$ & 0.064 & $17.905^{\star \star \star}$ & 1.094 & 0.486 \\
\hline $\begin{array}{l}\text { Other and unspecified heart } \\
\text { diseases (including alcoholic } \\
\text { cardiomyopathy) }\end{array}$ & $2.916^{\star \star \star}$ & 0.177 & $0.251^{*}$ & 0.171 & $-6.157^{* *}$ & 2.943 & 0.916 \\
\hline Tuberculosis & $1.929^{* \star *}$ & 0.151 & $0.563^{\star \star \star}$ & 0.145 & $12.951^{* \star *}$ & 2.500 & 0.878 \\
\hline Septicaemia & $0.085^{\star \star \star}$ & 0.010 & $0.033^{\star \star \star}$ & 0.009 & $0.132^{*}$ & 0.162 & 0.778 \\
\hline Homicide & $0.540^{\star * \star}$ & 0.119 & $0.475^{\star \star \star}$ & 0.114 & $12.825^{\star \star *}$ & 1.968 & 0.603 \\
\hline $\begin{array}{l}\text { njury, whether accidentally or } \\
\text { purposely inflicted is undetermined }\end{array}$ & $1.914^{\star \star \star}$ & 0.151 & $0.974^{\star \star \star}$ & 0.145 & $6.458^{* *}$ & 2.503 & 0.892 \\
\hline Suicide and self-inflicted injury & $0.172^{*}$ & 0.142 & $0.862^{\star *}$ & 0.137 & 55.161 & 2.357 & 0.622 \\
\hline $\begin{array}{l}\text { Other circulatory system } \\
\text { diseases }\end{array}$ & $0.256^{* \star *}$ & 0.019 & $0.099^{* *}$ & 0.018 & $11.651^{* * *}$ & 0.316 & 0.893 \\
\hline Other accidents & $0.688^{\star \star *}$ & 0.215 & $0.766^{\star \star}$ & 0.207 & $79.965^{\star \star \star}$ & 3.568 & 0.489 \\
\hline Gastric and duodenal ulcer & $-0.056^{* *}$ & 0.021 & $0.084^{* *}$ & 0.020 & $8.170^{* * *}$ & 0.350 & 0.490 \\
\hline Cerebrovascular diseases & $0.941^{* * *}$ & 0.199 & $0.893^{*}$ & 0.192 & $83.603^{\star \star \star}$ & 3.304 & 0.638 \\
\hline
\end{tabular}

Notes: ${ }^{1}$ Residuals from the regression of SDRs due to alcohol poisoning on time are used.

$\mathrm{N}=28 ; * * * \mathrm{p}<0.01, * * \mathrm{p}<0.05, * \mathrm{p}<0.10$

Source: author's calculations based on data from Meslé et al. (2008) and Statistical Office of Ukraine. 
Appendix 3: Results of linear regression of alcohol-related causes of death as a function of time and alcohol poisoning ${ }^{1}$, females (formula 3)

\begin{tabular}{|c|c|c|c|c|c|c|c|}
\hline Cause of death & $\alpha_{1}^{j}$ & SE & $\alpha_{2}^{j}$ & SE & $\alpha_{0}^{j}$ & SE & $\mathrm{R}^{2}$ \\
\hline Ischemic heart disease & $1.510^{\star \star \star}$ & 0.129 & $5.337^{\star \star *}$ & 0.638 & $61.764^{* * *}$ & 2.143 & 0.892 \\
\hline Influenza and pneumonia & $0.163^{\star \star \star}$ & 0.017 & $0.450^{\star \star \star}$ & 0.083 & $1.384^{\star * *}$ & 0.280 & 0.830 \\
\hline Accidental falls & $0.030^{\star \star *}$ & 0.004 & $0.086^{* * *}$ & 0.021 & $1.293^{* * *}$ & 0.071 & 0.727 \\
\hline $\begin{array}{l}\text { Other respiratory diseases } \\
\text { (excluding Influenza and } \\
\text { pneumonia) }\end{array}$ & $-0.356^{* * *}$ & 0.020 & $0.406^{\star \star \star}$ & 0.101 & $16.266^{* * *}$ & 0.338 & 0.928 \\
\hline Liver cirrhosis & $0.960^{\star * *}$ & 0.100 & $1.907^{* * *}$ & 0.495 & $1.945^{*}$ & 1.663 & 0.810 \\
\hline Diseases of the pancreas & $0.012^{\star \star \star}$ & 0.005 & $0.093^{\star \star \star}$ & 0.024 & $1.708^{\star \star *}$ & 0.081 & 0.777 \\
\hline Undetermined injury & $0.303^{* \star \star}$ & 0.029 & $0.559^{* * *}$ & 0.145 & $0.603^{*}$ & 0.487 & 0.829 \\
\hline $\begin{array}{l}\text { Accidental drowning and } \\
\text { submersion }\end{array}$ & $0.036^{\star \star *}$ & 0.007 & $0.097^{* * *}$ & 0.035 & $1.633^{* * *}$ & 0.118 & 0.574 \\
\hline $\begin{array}{l}\text { Other and unspecified heart } \\
\text { diseases, including alcoholic } \\
\text { cardiomyopathy }\end{array}$ & $0.674^{\star \star *}$ & 0.036 & $0.685^{\star * *}$ & 0.179 & $0.122^{*}$ & 0.601 & 0.935 \\
\hline Other accidents & $0.568^{* * *}$ & 0.048 & $0.618^{* *}$ & 0.235 & $15.962^{\star * *}$ & 0.789 & 0.608 \\
\hline Septicaemia & $0.034^{\star \star *}$ & 0.006 & $0.069^{* *}$ & 0.029 & $0.293^{* * *}$ & 0.097 & 0.613 \\
\hline
\end{tabular}

Notes: ${ }^{1}$ Residuals from the regression of SDRs due to alcohol poisoning on time are used.

$\mathrm{N}=28 ; * * * \mathrm{p}<0.01, * * \mathrm{p}<0.05, * \mathrm{p}<0.10$

Source: author's calculations based on data from Meslé et al. (2008) and Statistical Office of Ukraine. 